\title{
Intrathecal antibody production against Epstein-Barr and other neurotropic viruses in pediatric and adult onset multiple sclerosis
}

\author{
Daniela Pohl $\cdot$ Kevin Rostasy $\cdot$ Christian Jacobi $\cdot$ \\ Peter Lange $\cdot$ Roland Nau $\cdot$ Bernd Krone · \\ Folker Hanefeld
}

Received: 10 May 2009/Revised: 11 August 2009/Accepted: 12 August 2009/Published online: 28 August 2009

(C) Springer-Verlag 2009

\begin{abstract}
Epstein-Barr virus (EBV) has been implicated in the pathogenesis of multiple sclerosis (MS). Recent reports proposed an increased EBV-targeted humoral immune response in MS, which appears to be more pronounced in pediatric patients. However, little is known
\end{abstract}

D. Pohl $(\bowtie)$

Department of Neurology,

Children's Hospital of Eastern Ontario,

University of Ottawa, 401 Smyth Road,

Ottawa, ON K1H-8L1, Canada

e-mail: dpohl@cheo.on.ca

K. Rostasy

Division of Paediatric Neurology and

Inborn Errors of Metabolism, Department of Paediatrics,

Medical University Innsbruck, Innsbruck, Austria

C. Jacobi

Department of Neurology, University of Heidelberg,

Heidelberg, Germany

P. Lange $\cdot$ R. Nau

Neurochemistry Laboratory, Department of Neurology,

Georg August University Göttingen, Göttingen, Germany

Present Address:

R. Nau

Department of Geriatrics, Evangelisches Krankenhaus

Göttingen-Weende, Göttingen, Germany

B. Krone

Department of Virology, Georg August University Göttingen,

Göttingen, Germany

Present Address:

B. Krone

Laboratory Medicine Institute Kassel, Kassel, Germany

F. Hanefeld

Department of Paediatrics and Paediatric Neurology,

Georg August University Göttingen, Göttingen, Germany about the CNS-derived antibody production against EBV in patients with MS. The objective of this study was to assess the frequency and intensity of intrathecal antibody production against EBV as compared to other neurotropic viruses in pediatric and adult onset MS. In cohorts of 43 childhood, 50 adult onset MS patients, 20 children and 12 adults with other CNS disorders, paired CSF and serum samples were studied. Frequency and intensity of intrathecal antibody production against EBV as compared to measles, rubella, varicella zoster (VZV) and herpes simplex virus (HSV) were analyzed by determination of virus-specific CSF-to-serum Antibody Indices (AI). Intrathecally synthesized EBV antibodies were detectable in $26 \%$ pediatric and $10 \%$ adult onset MS patients, compared to frequencies ranging in both groups from 10 to $60 \%$ for the other viruses. Median AIs for EBV were lower than those for all other viruses, with more than twofold higher median AI for measles, rubella and VZV. The EBV-targeted humoral immune response in the CNS is only part of the intrathecal polyspecific antibody production in MS, directed against various neurotropic viruses. Our results do not rule out the possibility that EBV is involved in the pathogenesis of MS by triggering diverse cellular immune mechanisms, but they argue against a direct pathogenic role of EBVtargeted humoral immune response within the CNS.

Keywords Multiple sclerosis - Epstein-Barr virus · Intrathecal immunoglobulin production .

Neurotropic viruses $\cdot$ CNS humoral immune response

\section{Introduction}

Epstein-Barr virus (EBV) has been implicated in the pathogenesis of multiple sclerosis (MS) [1-19]. MS 
patients are reported to have higher EBV seropositivity rates and serum antibody concentrations compared to controls [4-11]. These MS-associated differences of the humoral immune response to EBV appear to be more pronounced in pediatric than in adult patients [8-10]. The mechanisms by which EBV may contribute to the etiology of MS are unknown. Recent reports proposed an increased EBV-targeted humoral immune response in the CNS of MS patients, but did not verify these findings in larger cohorts with CSF-specific methods [11, 12].

An intrathecal $\mathrm{IgG}$ production is a key feature of both MS and CNS infections. In neuroinfectious diseases like herpes simplex virus (HSV) encephalitis, neuroborreliosis, subacute sclerosing panencephalitis, varicella zoster virus (VZV) vasculopathy and ganglionitis, at least part of the intrathecally produced $\mathrm{IgG}$ is directed against the causative agent [20-23]. This specific intrathecal immune response is long-lasting and can be detected with high sensitivity via calculation of the CSF-to-serum Antibody Index (AI) [22-24].

The study of pediatric onset MS might provide better insights into the pathogenesis of the disease than that of adult onset MS: in comparison to adult MS patients, children with MS have a more restricted time window between exposure to putative environmental triggers like viral infections and clinical expression of the disease. Immunological fingerprints of potentially disease-relevant infections would therefore be expected to be more evident in pediatric than in adult MS patients.

To study the potential role of EBV in the pathoimmunology of MS, we determined the frequency and intensity of CNS-derived antibodies against EBV versus that of other common neurotropic viruses in childhood as compared to adult onset MS patients.

\section{Methods}

A total of 125 paired serum and CSF samples (43 patients with pediatric onset MS, 50 patients with adult onset MS, and 32 patients with other CNS disorders) were included in the study.

In the context of a longitudinal survey of MS patients with a disease onset prior to age 16 years, CSF and blood samples were obtained from children with MS at the time of first admission to the Department of Paediatric Neurology, University of Göttingen, Germany, between 1997 and 2004. Diagnosis of MS was established according to the criteria of Poser (before 2002) or McDonald (since 2002). Paired serum and CSF samples in sufficient quantity to perform the complete assessment of virus-specific intrathecal antibody responses were available from 43 children.
The pediatric control group contained 20 children with other CNS disorders, 10 of these patients had inflammatory (optic neuritis: 3, neuromyelitis optica: 2, unclassified chronic inflammatory CNS disease: 2, viral meningitis: 2, concentric sclerosis Baló: 1), 10 noninflammatory CNS diseases (headache/migraine: 2, astrocytoma: 2, seizures/ epilepsy: 2, psychosomatic disorders: 2, pseudotumor cerebri: 1, neuroacanthocytosis: 1 ).

The adult onset MS group was composed of 50 consecutive patients undergoing lumbar puncture and diagnosed as MS (McDonald criteria) with a manifestation at age 18 years or older, admitted to the Departments of Neurology of the Universities of Göttingen and Heidelberg, Germany, between 2004 and 2005.

The adult control group contained 12 patients with noninflammatory CNS disease (headache/migraine: 3, psychiatric disorders: 2, CNS metastases: 1, seizures: 1, pseudotumor cerebri: 1, cognitive deterioration: 1, intracranial hemorrhage: 1).

The study was approved by the Ethics Committee of the Medical Faculty, Georg August University, Göttingen, Germany.

DNA from CSF samples of 43 patients with childhood onset MS was extracted with QIAmp DNA Blood Mini Kit (Qiagen, Hilden, Germany), and analyzed by real-time PCR for the presence of EBV genome (EBV LC PCR kit, Artus, Hamburg, Germany; analytical sensitivity: 0.8 genome equivalents $/ \mu \mathrm{L}$, probit analysis $p=0.05$ ).

Serum and CSF samples were examined for virus-specific antibodies against EBV-encoded nuclear antigen-I (EBNA-I) and EBV-virus capsid antigen (EBV-VCA) by ELISA kits from DRG Instruments (Dietzenbach, Germany), and against measles, rubella, VZV and HSV by ELISA kits from Dade Behring (Marburg, Germany). Absorbances were measured with a microtiter plate reader (SLT Labinstruments, Crailsheim, Germany). Calibration curves were plotted by serial dilution of a pooled serum (6 serial dilutions of 1:2.3). The predilution of the highest standard concentration was chosen to obtain an optical density of approximately 2.0, defined as 100 arbitrary concentration units. Paired CSF and serum samples were analyzed in the same analytical run with reference to the standard curve. Standard sample dilutions, CSF (1:15) and serum $(1: 3,000)$, were chosen to produce absorbance values in the linear range of the standard curve. The measured absorbance was transferred into arbitrary concentration units, by reference to the standard curve [24].

Albumin and IgG in CSF and serum were analyzed by immunochemical nephelometry (Dade Behring Nephelometer, Marburg, Germany). Intrathecally synthesized virus-specific CSF antibodies were determined by calculation of the Antibody Index according to the formula: 
Antibody Index $(\mathrm{AI})=\frac{\text { virus-specific } \frac{\mathrm{IgG}_{\mathrm{CSF}}}{\mathrm{IgG}_{\text {Serum }}}}{\operatorname{total}_{\mathrm{IgG}} \frac{\operatorname{IgG}}{\mathrm{IgSF}}}$

In the presence of a quantitatively detectable intrathecal IgG production as identified by analysis of the CSF-toserum IgG versus albumin quotient diagram [22], a corrected AI was calculated according to Reiber and Lange [24]. The method-dependent, normal reference range of AI is $0.7-1.3(1.0 \pm 2 \mathrm{SD})$. Taking into account coefficients of variation, AI values $\geq 1.5$ indicate intrathecal antibody synthesis [22, 24].

\section{Results}

CSF cells and protein content

Pleocytosis ( $\geq 5$ cells $/ \mu \mathrm{L}$ ) was noticed in $56 \%$ childhood, $62 \%$ adult onset MS, $30 \%$ pediatric and $0 \%$ adult control patients. A total protein concentration $>450 \mathrm{mg} / \mathrm{L}$ was found in $16 \%$ childhood, $44 \%$ adult onset MS, $20 \%$ pediatric and $17 \%$ adult control patients (Table 1).

\section{EBV genome in CSF}

EBV genome was not detected in any of 43 CSF samples from childhood onset MS patients analyzed by real-time PCR.

Intrathecal synthesis of virus-specific antibodies

An intrathecal synthesis of at least one virus-specific antibody (measles, rubella, VZV, HSV, EBNA-I or EBVVCA) was detected in 31/43 (72\%) childhood and 41/50 (82\%) adult onset MS patients. None of 20 children and 12 adults with other CNS diseases presented intrathecally synthesized antibodies against this selection of common neurotropic viruses.

Frequency

Specific antibodies against EBNA-I were detected in 9 of 43 childhood and 4 of 50 adult onset MS patients, against EBV-VCA in 6 childhood and 1 adult onset MS patients (Table 2). Overall, 11 (26\%) childhood and 5 (10\%) adult onset MS patients had evidence of an intrathecal IgG synthesis against at least one EBV antigen. The corresponding frequencies for other neurotropic viruses were equal or higher, ranging in the childhood onset group from $26 \%$ (HSV) to $49 \%$ (VZV), in the adult onset group from $10 \%$ (HSV) to $60 \%$ (measles). All but one patient with an intrathecal IgG production against EBV also showed an intrathecal IgG response against at least one other virus.

Intensity

Median antibody indices (AI) for EBNA-I and EBV-VCA were lower than those for all other viruses, with more than twofold higher median AI for measles, rubella and VZV (Fig. 1).

\section{Discussion}

Our study revealed that only $26 \%$ of childhood and $10 \%$ of adult onset MS patients presented evidence for an intrathecal synthesis of EBV antibodies, as compared to percentages ranging from 30 to $60 \%$ for CNS-produced antibodies against measles, rubella and VZV. Moreover, median CSF specific antibody indices were not higher for EBNA-I or EBV-VCA than for the other neurotropic viruses, and CSF PCR results were consistently negative for EBV.

Table 1 Characteristics of patients with MS and other CNS diseases

\begin{tabular}{|c|c|c|c|c|}
\hline & \multicolumn{2}{|l|}{ Multiple sclerosis } & \multicolumn{2}{|l|}{ Other CNS diseases } \\
\hline & Pediatric onset $(n=43)$ & Adult onset $(n=50)$ & Children $(n=20)$ & Adults $(n=12)$ \\
\hline Gender: female/male $(n)$ & $30 / 13$ & $35 / 15$ & $11 / 9$ & $8 / 4$ \\
\hline Age at onset (years) ${ }^{\mathrm{a}}$ & 13.1/13.7 (7.9-15.9) & $34.2 / 35.6(18.2-54.6)$ & $11.6 / 12.0(6.9-15.7)$ & $44.6 / 43.7(20.4-70.3)$ \\
\hline Sample acquisition age (years) ${ }^{\mathrm{a}}$ & $14.7 / 14.8(10.5-17.9)$ & $37.1 / 38.5(20.2-58.6)$ & $12.3 / 13.1(7.0-16.4)$ & 45.4/44.6 (20.4-70.8) \\
\hline Sampling latency (years) ${ }^{\mathrm{a}}$ & $1.6 / 0.8(0.0-6.6)$ & $3.0 / 1.1(0.0-16.2)$ & $0.8 / 0.1(0.0-7.9)$ & $0.9 / 0.5(0.0-3.9)$ \\
\hline \multicolumn{5}{|l|}{ CSF findings } \\
\hline Leukocytes $(\text { cells } / \mu \mathrm{L})^{\mathrm{a}}$ & $11 / 5(0-75)$ & $11 / 6(0-95)$ & $3 / 1(0-15)$ & $1 / 1(0-4)$ \\
\hline Protein $(\mathrm{mg} / \mathrm{L})^{\mathrm{a}}$ & 347/338 (139-961) & 469/411 (146-992) & 325/295 (144-644) & 406/376 (203-915) \\
\hline Intrathecal IgG synthesis $(\%)^{\mathrm{a}}$ & $29 / 24(0-72)$ & $26 / 25(0-80)$ & $2 / 0(0-33)$ & $0 / 0(0-0)$ \\
\hline Oligoclonal $\operatorname{IgG}(n)$ & 42 & 50 & 2 & 0 \\
\hline
\end{tabular}

${ }^{\mathrm{a}}$ Mean/median (range) 
Table 2 Frequency of intrathecal antibody response (Antibody Index $\geq 1.5$ ) against measles, rubella, varicella zoster, herpes simplex and Epstein-Barr virus in patients with pediatric onset MS $(n=43)$ and adult onset MS $(n=50)$

\begin{tabular}{lll}
\hline Antibody species & \multicolumn{2}{l}{ Intrathecal antibody } \\
\cline { 2 - 3 } & $\begin{array}{l}\text { Pediatric onset } \\
\text { MS (\%) }\end{array}$ & $\begin{array}{l}\text { Adult onset } \\
\text { MS (\%) }\end{array}$ \\
\hline Measles & 35 & 60 \\
Rubella & 30 & 42 \\
Varicella zoster & 49 & 32 \\
Herpes simplex & 26 & 10 \\
Epstein-Barr virus & 21 & 8 \\
$\quad$ nuclear antigen (EBNA-I) & & 2 \\
Epstein-Barr virus & 14 & \\
capsid antigen (EBV-VCA) & & \\
\hline
\end{tabular}
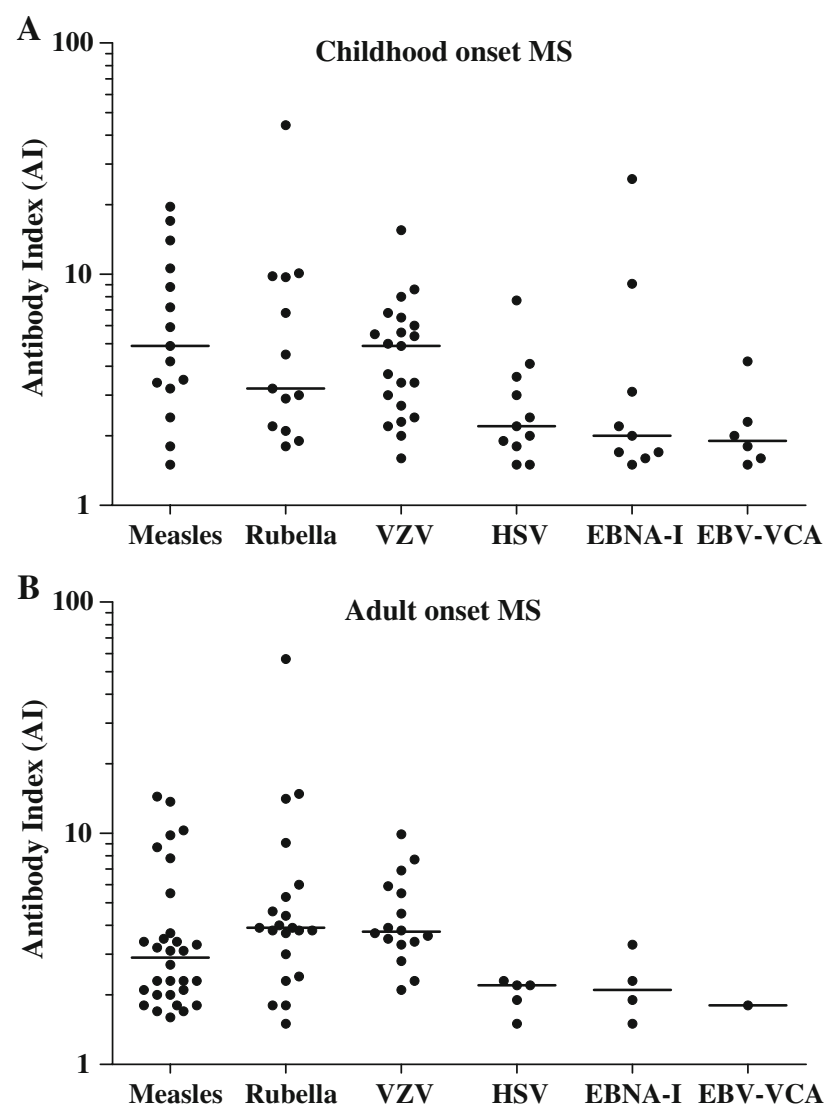

Fig. 1 Distribution of virus-specific CSF antibody indices (AI) of (a) childhood onset and (b) adult onset MS patients with intrathecal antibody synthesis $(\mathrm{AI} \geq 1.5)$ against measles, rubella, varicella zoster (VZV), herpes simplex (HSV) or Epstein-Barr virus (EBNA-I and EBV-VCA). Horizontal bars mark median AI values. Median AI for EBNA-I and EBV-VCA were lower than for the other neurotropic viruses

It is evident that a negative PCR for EBV in the CSF does not exclude a prior EBV infection of the CNS in our patients. Based on the experience with other infectious
CNS diseases, it is well known that PCR is often only transiently positive shortly after infection, as in HSV encephalitis. By contrast, in later disease stages, detection of microbe-specific intrathecal antibody synthesis has been proven a stable and sensitive diagnostic method in various infectious CNS diseases [22, 23]. In neuroborreliosis, the diagnostic sensitivity of the PCR is well below $40 \%$, whereas more than $80 \%$ of patients show intrathecally produced antibodies against Borrelia burgdorferi [22].

Using the sensitive method of intrathecal IgG synthesis determination, our study revealed that only a minority of MS patients intrathecally produced IgG antibodies against EBV. In contrast, a recent study described an increased $\operatorname{IgG}$ immune response to EBV protein EBNA-I in the CSF of MS patients as compared to controls [11]. However, this study did not determine whether the EBNA-I antibodies in the CSF were intrathecally produced or carried over from blood. Thus, the reported increased CSF levels of antiEBNA-I IgG might have been merely the consequence of diffusion of serum-derived antibodies into the CSF, since elevated anti-EBNA-I serum concentrations are a known phenomenon in MS [5-9].

The fact that intrathecally produced EBV antibodies were absent in over $80 \%$ of our MS patients strongly argues against a direct role for EBV in the humoral immune response of the CNS in MS. Furthermore, median CSF specific antibody indices (AI) were not higher for EBNA-I or EBV-VCA than for the other common neurotropic viruses analyzed. The mean AI for EBNA-I was 2, and for EBV-VCA 4, as compared to a mean Borrelia burgdorferi AI of 43 recently reported for patients with neuroborreliosis [21].

In our study, CNS-produced antibodies against measles, rubella or VZV were detectable in frequencies between 30 and $60 \%$ of pediatric and adult MS patients. All but one patient with an intrathecal IgG production against EBV also showed an intrathecal $\mathrm{IgG}$ response against at least one of these other viruses. These findings indicate that intrathecally produced antibodies against EBV antigens are only part of the known polyspecific CNS antibody production in MS, directed against diverse common neurotropic viruses [21-23].

Cell mediated immune mechanisms, involving $\mathrm{T}$ - and NK-cells, are of pivotal importance in controlling the proliferation of EBV-infected B cells, and $\mathrm{T}$ cell crossrecognition between EBV and myelin antigens has been demonstrated [16, 17]. Moreover, a strong EBV-specific $\mathrm{CD} 8+\mathrm{T}$ cell response in patients with early MS has been reported recently [18]. Our results do not rule out the possibility that EBV is involved in the pathogenesis of MS by triggering diverse cellular immune mechanisms, but they argue against a direct pathogenic role of EBV-targeted humoral immune response in the CNS. 
Acknowledgments The authors thank Drs. H. Reiber, E. Bollensen, B. Daelen, P. Gensicke, W. Lüer and K. Radau-Pfeil for their kind support. This work was supported by a grant of the Hertie-Stiftung (GHS 191/00).

\section{References}

1. Pohl D (2009) Epstein-Barr virus and multiple sclerosis. J Neurol Sci [epub ahead of print]

2. Krone B, Oeffner F, Grange JM (2009) Is the risk of multiple sclerosis related to the 'biography' of the immune system? J Neurol 256:1052-1060

3. Martyn CN, Cruddas M, Compston DAS (1993) Symptomatic Epstein-Barr virus infection and multiple sclerosis. J Neurol Neurosurg Psychiatry 56:167-168

4. Myhr KM, Riise T, Barrett-Connor E, Myrmel H, Vedeler C, Gronning $\mathrm{M}$ et al (1998) Altered antibody pattern to Epstein-Barr virus but not to other herpesviruses in multiple sclerosis: a population based case-control study from western Norway. J Neurol Neurosurg Psychiatry 64:539-542

5. Buljevac D, van Doornum GJJ, Flach HZ, Groen J, Osterhaus $\mathrm{AD}$, Hop W et al (2005) Epstein-Barr virus and disease activity in multiple sclerosis. J Neurol Neurosurg Psychiatry 76:1377-1381

6. DeLorenze GN, Munger KL, Lennette ET, Orentreich N, Vogelman JH, Ascherio A (2006) Epstein-Barr virus and multiple sclerosis: evidence of an association from a prospective study with long-term follow-up. Arch Neurol 63:839-844

7. De Jager PL, Simon KC, Munger KL, Rioux JD, Hafler DA, Ascherio A (2008) Integrating risk factors: HLA-DRB1*1501 and Epstein-Barr virus in multiple sclerosis. Neurology 70:11131118

8. Banwell B, Krupp L, Kennedy J, Tellier R, Tenembaum S, Ness J et al (2007) Clinical features and viral serologies in children with multiple sclerosis: a multinational observational study. Lancet Neurol 6:773-781

9. Pohl D, Krone B, Rostasy K, Kahler E, Brunner E, Lehnert M et al (2006) High seroprevalence of Epstein-Barr Virus in children with multiple sclerosis. Neurology 67:2063-2065

10. Alotaibi S, Kennedy J, Tellier R, Stephens D, Banwell B (2004) Epstein-Barr virus in pediatric multiple sclerosis. JAMA 291:1875-1879

11. Cepok S, Zhou D, Srivastava R, Nessler S, Stei S, Büssow K et al (2005) Identification of Epstein-Barr virus proteins as putative targets of the immune response in multiple sclerosis. J Clin Invest 115:1352-1360
12. Rand KH, Houck H, Denslow ND, Heilman KM (2000) EpsteinBarr virus nuclear antigen-1 (EBNA-1) associated oligoclonal bands in patients with multiple sclerosis. J Neurol Sci 173:32-39

13. Lünemann JD, Edwards N, Muraro PA, Hayashi S, Cohen JI, Munz C, Martin R (2006) Increased frequency and broadened specificity of latent EBV nuclear antigen-I-specific T-cells in multiple sclerosis. Brain 129:1493-1506

14. Thacker EL, Mirzaei F, Ascherio A (2006) Infectious mononucleosis and risk for multiple sclerosis: a meta-analysis. Ann Neurol 59:499-503

15. Nielsen TR, Rostgaard K, Nielsen NM, Frisch M, Hjalgrim $H$ (2007) Multiple sclerosis after infectious mononucleosis. Arch Neurol 64:72-75

16. Holmoy T, Kvale EO, Vartdal F (2004) Cerebrospinal fluid CD4+ $\mathrm{T}$ cells from a multiple sclerosis patient cross-recognize EpsteinBarr virus and myelin basic protein. J Neurovirol 10:278-283

17. Lünemann JD, Jelcic I, Roberts S, Lutterotti A, Tackenberg B, Martin R et al (2008) EBNA1-specific T cells from patients with multiple sclerosis cross react with myelin antigens and co-produce IFN-gamma and IL-2. J Exp Med 205:1763-1773

18. Jilek S, Schluep M, Meylan P, Vingerhoets F, Guignard L, Monney A et al (2008) Strong EBV-specific CD8+ T-cell response in patients with early multiple sclerosis. Brain 131:1712-1721

19. Serafini B, Rosicarelli B, Franciotta D, Magliozzi R, Reynolds R, Cinque P et al (2007) Dysregulated Epstein-Barr infection in the multiple sclerosis brain. J Exp Med 204:2899-2912

20. Burgoon MP, Hammack BN, Owens GP, Maybach AL, Eikelenboom MJ, Gilden DH (2003) Oligoclonal immunoglobulins in cerebrospinal fluid during varicella zoster virus (VZV) vasculopathy are directed against VZV. Ann Neurol 54:459-463

21. Derfuss T, Gürkov R, Then Bergh F, Goebels N, Hartmann M, Barz C et al (2001) Intrathecal antibody production against Chlamydia pneumoniae in multiple sclerosis is part of a polyspecific immune response. Brain 124:1325-1335

22. Reiber H, Peter JB (2001) Cerebrospinal fluid analysis: diseaserelated data patterns and evaluation programs. J Neurol Sci 184:101-122

23. Jacobi C, Lange P, Reiber H (2007) Quantitation of intrathecal antibodies in cerebrospinal fluid of subacute sclerosing panencephalitis, herpes simplex encephalitis and multiple sclerosis: discrimination between microorganism-driven and polyspecific immune response. J Neuroimmunol 187:139-146

24. Reiber H, Lange P (1991) Quantification of virus-specific antibodies in cerebrospinal fluid and serum: sensitive and specific detection of antibody synthesis in the brain. Clin Chem 37:11531160 